CrossMark \&click for updates

Cite this: Phys. Chem. Chem. Phys., 2015, 17, 12587

Received 27th February 2015 Accepted 7th April 2015

DOI: $10.1039 / c 5 c p 01187 f$

www.rsc.org/pccp

\section{Oxygen diffusion in single crystal barium titanate}

\author{
Markus Kessel, Roger A. De Souza* and Manfred Martin
}

\begin{abstract}
Oxygen diffusion in cubic, nominally undoped, (100) oriented $\mathrm{BaTiO}_{3}$ single crystals has been studied by means of ${ }^{18} \mathrm{O}_{2} /{ }^{16} \mathrm{O}_{2}$ isotope exchange annealing and subsequent determination of the isotope profiles in the solid by time-of-flight secondary ion mass spectrometry (ToF-SIMS). Experiments were carried out as a function of temperature $973<\mathrm{T} / \mathrm{K}<1173$, at an oxygen activity of $\mathrm{aO}_{2}=0.200$, and as a function of oxygen activity $0.009<\mathrm{aO}_{2}<0.900$ at $T=1073 \mathrm{~K}$. The oxygen isotope profiles comprise two parts: slow diffusion through a space-charge zone at the surface depleted of oxygen vacancies followed by faster diffusion in a homogeneous bulk phase. The entire isotope profile can be described by a single solution to the diffusion equation involving only three fitting parameters: the surface exchange coefficient $k_{s}{ }^{*}$, the space-charge potential $\Phi_{0}$ and the bulk diffusion coefficient $D^{*}(\infty)$. Analysis of the temperature and oxygen activity dependencies of $D^{*}(\infty)$ and $\Phi_{0}$ yields a consistent picture of both the bulk and the interfacial defect chemistry of $\mathrm{BaTiO}_{3}$. Values of the oxygen vacancy diffusion coefficient $D_{\vee}$ extracted from measured $D^{*}(\infty)$ data are compared with literature data; consequently a global expression for the vacancy diffusivity in $\mathrm{BaTiO}_{3}$ for the temperature range $466<\mathrm{T} / \mathrm{K}<1273$ is obtained, with an activation enthalpy of vacancy migration, $\Delta H_{\text {mig, } v}=(0.70 \pm 0.04) \mathrm{eV}$.
\end{abstract}

\section{Introduction}

Barium titanate, $\mathrm{BaTiO}_{3}$, is a perovskite-type oxide that finds application in various modern electroceramic technologies, such as multilayer ceramic capacitors (MLCCs) ${ }^{1-5}$ ferroelectric random access memories (FRAM), ${ }^{6,7}$ and (positive temperature coefficient) PTC resistors. ${ }^{8,9}$ In all these applications the migration of oxygen vacancies is thought to play a central role, either in producing and preparing devices for use, or conversely, in determining degradation and failure mechanisms. As a consequence, the migration of oxygen vacancies in various $\mathrm{BaTiO}_{3}$ systems has been studied with a variety of methods. On the macroscopic level, equilibrium ion conductivities $\sigma_{\text {ion }},{ }^{10,11}$ chemical diffusion coefficients $D^{\delta 12}$ and tracer diffusion coefficients $D^{* 13-18}$ have been measured for nominally undoped, ${ }^{19-24}$ donor-doped,,$^{20,25}$ and acceptor-doped ${ }^{23}$ polycrystalline materials and for nominally undoped ${ }^{21,24}$ and acceptor-doped ${ }^{26}$ single crystals. On the microscopic level, vacancy motion has been examined by electron paramagnetic resonance (EPR), ${ }^{27}$ relaxation techniques, ${ }^{28-31}$ and classical $^{32,33}$ and quantum mechanical ${ }^{34}$ simulations. There is, however, considerable scatter in both the magnitude of the vacancy diffusivity $D_{\mathrm{V}}$ at given temperature, and its temperature dependence, namely the vacancy migration enthalpy, $\Delta H_{\text {mig,v }}$.

Institut für Physikalische Chemie, RWTH Aachen University, Landoltweg 2, 52056 Aachen, Germany. E-mail: desouza@pc.rwth-aachen.de; Fax: +4924180 94739; Tel: +492418092128
In this study we examined oxygen tracer diffusion in cubic, nominally undoped, (100) oriented $\mathrm{BaTiO}_{3}$ single crystals by means of ${ }^{18} \mathrm{O}_{2} /{ }^{16} \mathrm{O}_{2}$ isotope exchange annealing and subsequent determination of the isotope profiles in the solid by time-offlight secondary ion mass spectrometry (ToF-SIMS). Although the technique is well established, ${ }^{35-37}$ its application to single crystal $\mathrm{BaTiO}_{3}$ is far from trivial because of two phase transitions that the material undergoes. These transitions are from the hightemperature, cubic, paraelectric phase to a tetragonal, ferroelectric phase at $T=393 \mathrm{~K}$, and then to an orthorhombic ferroelectric phase at $T=283 \mathrm{~K}$ (a further transition to a rhombohedral phase at $T=183 \mathrm{~K}$ is of no relevance here). ${ }^{38,39}$ The $\mathrm{t} \rightarrow \mathrm{o}$ transition is a problem as it results in the catastrophic destruction of single crystals. Samples have to be kept, therefore, above this temperature for the entire duration of the experiment, including the ToF-SIMS analysis. The $\mathrm{c} \rightarrow \mathrm{t}$ transition presents problems, essentially because of the appearance of the ferroelectric domains. Single crystals of barium titanate are, on account of the ferroelectric domains, much more difficult to polish and typically show a higher surface roughness than other perovskite oxide single crystals, such as $\mathrm{SrTiO}_{3}$. Furthermore, upon cooling samples down from the high temperatures of the isotope annealing experiments to room temperature, ferroelectric domains form, and these are often small and numerous, which exacerbates charge compensation of insulating barium titanate during SIMS analysis. Poor charge compensation leads to switching of domains and, in the worst case, to microcracking of the samples. ${ }^{40}$ 
An additional complexity in investigating oxygen transport in cubic, acceptor-doped $\mathrm{BaTiO}_{3}$ is the possible presence of an equilibrium space-charge layer at the surface. This possibility has been ignored in the literature up to now, but given the evidence for such space-charge layers at the surfaces of both $\mathrm{SrTiO}_{3}$ (ref. 41-44) and $\mathrm{PbZr}_{x} \mathrm{Ti}_{1-x} \mathrm{O}_{3}{ }^{45}$ the presence at the (100) surface of $\mathrm{BaTiO}_{3}$ is to be expected. The tracer diffusion coefficient within the space-charge layer is position dependent and lower than in the bulk. Thus, a correct description of the isotope diffusion profiles requires the analysis of isotope diffusion through the surface space-charge layer.

The aim of this study is to use tracer diffusion experiments to characterize oxygen transport in $\mathrm{BaTiO}_{3}$ and to obtain a consistent description of both the bulk and the interfacial defect chemistry of $\mathrm{BaTiO}_{3}$. The former is realised by analysing the dependence of the tracer diffusion coefficient $D^{*}(\infty)$ on temperature $T$ and oxygen activity $a \mathrm{O}_{2}$; the latter, by analysing the dependence of the space-charge potential $\Phi_{0}$ on temperature $T$ and oxygen activity $a \mathrm{O}_{2}$.

\section{Concentrations of point defects}

One characteristic of alkaline earth titanate perovskites is that nominally undoped samples are in fact weakly acceptor-doped from impurities. ${ }^{23,46,47}$ The single crystal samples of $\mathrm{BaTiO}_{3}$ used in this study are no different: chemical analyses (see Section 4) and the experimentally determined bulk diffusion coefficients (see Section 5.3) confirm the presence of a small amount of a fixed valent acceptor dopant.

\subsection{Bulk defect chemistry}

The charge neutrality equation for acceptor-doped $\mathrm{BaTiO}_{3}$ under dry conditions at $T<1273 \mathrm{~K}$ reads

$$
c_{\mathrm{dop}}+c_{\mathrm{e}^{\prime}}=2 c_{\mathrm{v}_{\mathrm{o}}}+c_{\mathrm{h}},
$$

where $c_{\text {def }}$ is the concentration of defect def. $c_{\text {dop }}$ is the effective dopant concentration of acceptor-like species (and includes impurity cations and frozen-in cation vacancies minus the concentration of donors)

$$
c_{\text {dop }}=\sum_{\mathrm{A}}\left|z_{\text {def }}\right| c_{\mathrm{A}_{\mathrm{Ti}}}^{\left.z_{\text {def }}\right|^{\prime}}+2 c_{\mathrm{V}_{\mathrm{Ba}}^{\prime \prime}}+4 c_{\mathrm{V}_{\mathrm{Ti}}^{\prime \prime \prime \prime}}-\left.\sum_{\mathrm{D}}\left|z_{\text {def }}\right| c_{\mathrm{D}}\right|_{\text {def }} \mid \cdot
$$

( $z_{\text {def }}$ is the charge number of the defect). The other point defects of importance are oxygen vacancies $\left(\mathrm{V}_{\mathrm{O}}^{\bullet \bullet}\right)$, electrons $\left(\mathrm{e}^{\prime}\right)$ and electron holes $\left(\mathrm{h}^{\bullet}\right)$, and their concentrations are governed by two defect chemical equilibria: ${ }^{26}$

(1) the reduction of the oxide creating oxygen vacancies and electrons

$$
\mathrm{O}_{\mathrm{O}}^{\times} \rightleftharpoons \frac{1}{2} \mathrm{O}_{2}(\mathrm{~g})+\mathrm{V}_{\mathrm{O}}^{\bullet \bullet}+2 \mathrm{e}^{\prime}
$$

with the equilibrium constant of the reduction

$$
K_{\text {Red }}(T)=\left(a \mathrm{O}_{2}\right)^{1 / 2} c_{\mathrm{V}_{\mathrm{O}}}\left(c_{\mathrm{e}^{\prime}}\right)^{2}
$$

where $a \mathrm{O}_{2}$ is the activity of oxygen.

(2) the generation of electrons and holes by thermal excitation across the band gap

$$
0 \rightleftharpoons \mathrm{e}^{\prime}+\mathrm{h}^{\bullet}
$$

with the intrinsic electronic excitation equilibrium constant

$$
K_{\mathrm{i}}(T)=c_{\mathrm{e}^{\prime}} c_{\mathrm{h}} \cdot
$$

Combining eqn (1), (4) and (6) one can calculate defect concentrations in the bulk phase as a function of $T, \mathrm{aO}_{2}$ and $c_{\mathrm{dop}}$. Various sets of numerical parameters for the equilibrium constants $K_{\mathrm{Red}}(T)$ and $K_{\mathrm{i}}(T)$ are given in the literature. ${ }^{25,26,48,49}$ Here the values given by Song and Yoo are used.

For the range of temperatures and oxygen activities present in this study, eqn (1) may be approximated as

$$
c_{\mathrm{dop}} \approx 2 c_{\mathrm{v}_{\mathrm{o}}}>c_{\mathrm{h}} \cdot \gg c_{\mathrm{e}^{\prime}},
$$

i.e., acceptor dopants are compensated by oxygen vacancies in the bulk phase. This approximation is not necessarily valid for the surface space-charge zone.

\subsection{Interfacial defect chemistry}

We consider the single crystal as a two-phase system: a thin, structurally different surface region (interface core) in contact with a semi-infinite bulk phase. We assume that the Gibbs formation energy of the point-defect building unit $\{$ def $\}, g_{\{\text {def }}$, will change abruptly across the junction between core and bulk phases. ${ }^{50}$ If the building unit $\{$ def $\}$ is sufficiently mobile, it will redistribute between these two phases. At the end of the redistribution process, the core will be electrostatically charged, with the compensating space-charge zone in the adjacent bulk region. Fig. 1 shows schematically the situation for the case of vacancy re-distribution from bulk to core driving space-charge formation in acceptor-doped $\mathrm{BaTiO}_{3}$.

An equilibrium space-charge layer has formed when the electrochemical potentials of all mobile defects are constant throughout the system, $\nabla \tilde{\mu}_{\{\text {def }\}}=0 .{ }^{42,50,51}$ We assume that the electrochemical potential of building unit $\{$ def $\}$ in the bulk and in the interface core takes the standard form. ${ }^{51,52}$ Consequently one can relate the thermodynamic driving energies $\Delta g_{\{\text {def }\}}$ to the space-charge potential $\Phi_{0}$ :

$$
k_{\mathrm{B}} T \ln \frac{c_{\mathrm{def}}^{\mathrm{c}}}{N_{\mathrm{def}}^{\mathrm{c}}-c_{\mathrm{def}}^{\mathrm{c}}}-k_{\mathrm{B}} T \ln \frac{c_{\mathrm{def}}^{\mathrm{b}}}{N_{\mathrm{def}}^{\mathrm{b}}-c_{\mathrm{def}}^{\mathrm{b}}}+\Delta g_{\{\mathrm{def}\}}+z_{\mathrm{def}} e \Phi_{0}=0,
$$

where $N_{\text {def }}$ is the density of available sites for the building unit $\{$ def $\}$.

As the space charge is compensated exactly by the charge of the surface core, we can write: $Q_{\mathrm{sc}}+Q_{\mathrm{c}}=0$; or explicitly,

$$
\left.\varepsilon_{0} \varepsilon_{\mathrm{r}} \frac{\mathrm{d} \phi}{\mathrm{d} x}\right|_{x=0}+w_{\mathrm{c}} \sum_{\text {def }} z_{\text {def }} e\left(c_{\text {def }}^{\mathrm{c}}-c_{\text {def }}^{\mathrm{b}}\right)=0,
$$

where $w_{\mathrm{c}}$ is the thickness of the core. $Q_{\mathrm{sc}}[i . e$. the first term in eqn (9)] is obtained from the solution of the Poisson equation, which connects the electrical potential profile in the spacecharge layer to the point-defect distributions:

$$
\varepsilon_{0} \varepsilon_{\mathrm{r}} \frac{\mathrm{d}^{2} \phi}{\mathrm{d} x^{2}}=-e \sum_{\text {def }} z_{\operatorname{def}} c_{\text {def }}^{\mathrm{b}}(x),
$$



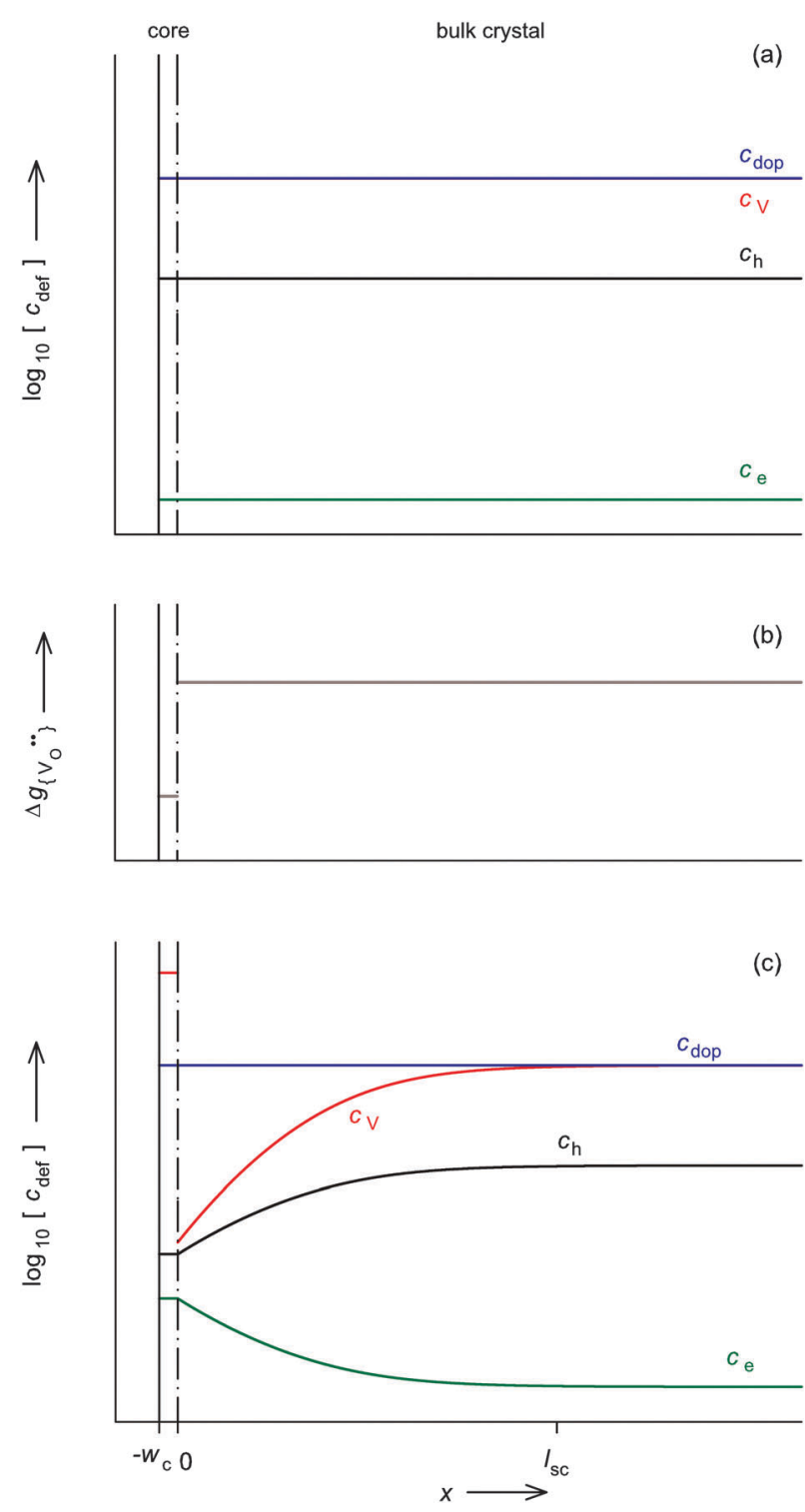

Fig. 1 Schematic illustration of space-charge formation at the surface of an ionic solid, based on the abrupt (corelspace-charge) model. ${ }^{50}$ After cleaving a crystal to form a surface at a sufficiently low temperature, we recognise that (a) defect concentrations remain unaltered, but relaxation of the uppermost atomic layers generates a structurally different region, the core $\left(-w_{c} \leq x \leq 0\right)$, in which (b) the standard chemical potential of oxygen vacancies (as building units) is lower than in the bulk, $\Delta g_{\mathbb{N}\}}=g_{i v\}}^{c}-g_{i v\}}^{b}<0$. Allowing the oxygen vacancies to redistribute by raising the sample to an intermediate temperature leads to (c) the formation of an equilibrium Mott-Schottky space-charge layer. $l_{\text {sc }}$ represents the extent of the space-charge layer. ${ }^{42}$

The two boundary conditions are $\phi(0)-\phi(\infty)=\Phi_{0}$ and $\nabla \phi(\infty)=0 . \varepsilon_{0} \varepsilon_{\mathrm{r}}$ is the dielectric permittivity [with $\varepsilon_{\mathrm{r}}=1.2 \times$ $\left.10^{5} /(T / \mathrm{K}-393)\right] .^{39}$

In essence, $\Phi_{0}$ and $c_{\text {def }}^{c}$ are calculated by solving eqn (8)-(10) numerically in a self-consistent fashion, for given $a \mathrm{O}_{2}, T$ and $c_{\text {dop }}$, with $\Delta g_{\{\text {def }\}}, N_{\text {def }}$, and $c_{\text {def }}^{\mathrm{b}}$ as input parameters.

In this study, the following values were used: the interface core width $w_{\mathrm{c}}=a / 2, N_{\mathrm{V}_{\mathrm{O}}, \mathrm{c}}=N_{\mathrm{V}_{\mathrm{O}}, \mathrm{b}}=4.69 \times 10^{28} \mathrm{~m}^{-3}, N_{\mathrm{h}, \mathrm{c}}=$ $N_{\mathrm{h}^{\bullet}, \mathrm{b}}=4.69 \times 10^{28} \mathrm{~m}^{-3}$ and $N_{\mathrm{e}^{\prime}, \mathrm{c}}=N_{\mathrm{e}^{\prime}, \mathrm{b}}=1.56 \times 10^{28} \mathrm{~m}^{-3}$.

\section{Tracer diffusion through space- charge layers}

An oxygen isotope anneal experiment consists, first, of bringing the oxide sample into equilibrium with the gas phase, and subsequently during the isotope anneal, of exchanging isotopes between the sample and the gas phase. This means that defect concentrations in the equilibrium space-charge layer do not change during the isotope anneal. As a consequence one can treat tracer diffusion though an equilibrium space-charge layer in two, separate steps: ${ }^{42}$

(1) In the first step point-defect concentrations in the spacecharge zone are calculated by solving Poisson's equation of electrostatics:

$$
\begin{aligned}
\varepsilon_{0} \varepsilon_{\mathrm{r}} \nabla^{2} \phi= & e c_{\mathrm{dop}}(x)-2 e c_{\mathrm{V}_{\mathrm{O}} \cdot}(x)-e c_{\mathrm{h}} \cdot(x)+e c_{\mathrm{e}^{\prime}}(x) \\
= & e c_{\mathrm{dop}}(x)-2 e c_{\mathrm{V}_{\mathrm{O}} \cdot}(\infty) \mathrm{e}^{\frac{-2 e\{\phi(x)-\phi(\infty)\}}{k_{\mathrm{B}} T}} \\
& -e c_{\mathrm{h}} \cdot(\infty) \mathrm{e}^{\frac{-e\{\phi(x)-\phi(\infty)\}}{k_{\mathrm{B}} T}}+e c_{\mathrm{e}^{\prime}}(\infty) \mathrm{e}^{\frac{e\{\phi(x)-\phi(\infty)\}}{k_{\mathrm{B}} T}} .
\end{aligned}
$$

(2) In the second step, the isotope diffusion profile is obtained by solving the diffusion equation with a position-dependent tracer diffusion coefficient $D^{*}(x)$ obtained in the first step,

$$
D^{*}(x)=f^{*} D_{\mathrm{V}} \frac{c_{\mathrm{V}_{\mathrm{O}} \cdot}(x)}{c_{\mathrm{O}_{\mathrm{O}}^{\times}}(x)} \approx D^{*}(\infty) \mathrm{e}^{\frac{-2 e\{\phi(x)-\phi(\infty)\}}{k_{\mathrm{B}} T}},
$$

where $f^{*}$ is the tracer correlation coefficient (and for an $\mathrm{ABO}_{3}$ perovskite-type oxide $\left.f^{*}=0.69\right)^{53}$ and $D_{\mathrm{V}}$ is the oxygen-vacancy diffusion coefficient. As demonstrated in ref. 42 the diffusion equation for the isotope fraction $n^{*}$ results as

$$
\begin{aligned}
\frac{\partial n^{*}(x, t)}{\partial t}= & -\frac{2 e \nabla \phi(x)}{k_{\mathrm{B}} T} D^{*}(x)\left(1-\frac{c_{\mathrm{V}_{\mathrm{O}}^{*}}(x)}{c_{\mathrm{O}_{\mathrm{O}}^{\times}}(x)}\right) \nabla n^{*}(x, t) \\
& +D^{*}(x) \nabla^{2} n^{*}(x, t) .
\end{aligned}
$$

For this second step of the numerical procedure two boundary conditions and an initial condition are required. The boundary conditions were $n^{*}(\infty, t)=n_{\mathrm{bg}}{ }^{*}$ with the natural abundance of the tracer $n_{\mathrm{bg}}{ }^{*}=0.002$ and an equation for the incorporation of the tracer at the gas-solid interface, ${ }^{54}$

$$
-\left.D_{\mathrm{O}^{*}}(0) \nabla n^{*}(x, t)\right|_{x=0}=k_{\mathrm{s}}{ }^{*}\left[n_{\mathrm{g}}{ }^{*}-n^{*}(0, t)\right],
$$

where $k_{\mathrm{s}}^{*}$ is the isotope surface exchange coefficient (and includes transport through the core between $x=-w_{\mathrm{c}}$ and $x=0)$ and $n_{\mathrm{g}}{ }^{*}$ the isotope fraction in the gas phase. The initial distribution of the labelled isotope $n^{*}(x, 0)$ is given by the natural abundance of ${ }^{18} \mathrm{O}, n_{\mathrm{bg}}{ }^{*}=0.002$.

Calculation of the entire theoretical tracer diffusion profile in these two steps was done numerically with COMSOL Multiphysics 3.5A (COMSOL AB, Stockholm, Sweden), which is based on the finite element method. Within the geometry of a semiinfinite medium the mesh sizes were varied: whereas the mesh was chosen to be very fine within the space-charge zone, much coarser mesh sizes were used for the bulk region. A test series 
showed that the computing times could be reduced drastically while keeping the required accuracy in terms of spatial resolution without any numerical artefacts.

\section{Experimental}

\subsection{Analyzed samples}

Single crystal slabs of (100) oriented, nominally undoped barium titanate, polished to dimensions of $5 \mathrm{~mm} \times 5 \mathrm{~mm} \times$ $0.5 \mathrm{~mm}$, were obtained from CrysTec $\mathrm{GmbH}$ (Berlin, Germany).

One of the samples was analyzed by laser ablation inductively coupled plasma mass spectrometry (LA-ICP-MS) at the Forschungszentrum Jülich, Germany on a Agilent 7500ce (Agilent Technologies, Inc., Santa Clara, CA, USA) with NewWave UP266 (Electro Scientific Industries, Inc., Portland, OR, USA). In Table 1 the found impurities are listed, together with assumed oxidation state and effective acceptor dopant level. As the applied ICP-MS measurements are semi-quantitative, all values are given with an error of $\pm 50 \%$. Nevertheless, the method is sufficient to identify the impurity elements and to determine their approximate concentrations: the total effective concentration of acceptor dopants is $(304 \pm 152)$ ppm or $(4.7 \pm$ 2.4) $\times 10^{24} \mathrm{~m}^{-3}$, with $\mathrm{Zn}$ showing the highest concentration.

\subsection{Isotope exchange experiments}

Prior to the isotope exchanges, the polished $\mathrm{BaTiO}_{3}$ samples were equilibrated for a duration of ten times the exchange time at the required $a \mathrm{O}_{2}$ in oxygen of natural isotopic abundance. Then the samples were annealed for a time $t_{\mathrm{ex}}$ in ${ }^{18} \mathrm{O}$-enriched oxygen gas at the same $a \mathrm{O}_{2}$ and $T$. Even for the lowest $a \mathrm{O}_{2}$, the volume of the exchange apparatus was large enough such that negligible depletion of ${ }^{18} \mathrm{O}$ from the gas phase occurred during the exchanges. ${ }^{56}$ The sample temperature was monitored by a $\mathrm{Pt}-\mathrm{Pt} / \mathrm{Rh}$ thermocouple situated directly under the sample. Diffusion times were corrected for heating and cooling periods.

\subsection{SIMS isotope analysis}

All diffusion profiles were measured by time-of-flight secondary ion mass spectrometry (ToF-SIMS) on a TOF-SIMS IV machine (ION-TOF GmbH, Münster, Germany). For all ToF-SIMS

Table 1 Impurity elements, oxidation states as dopants in perovskites, likely site, concentration in weight-ppm and effective concentration as acceptor dopant $\mathrm{Ac}_{\mathrm{Ti}}^{\prime}$ determined by ICP-MS analysis

\begin{tabular}{lllll}
\hline Element & $\begin{array}{l}\text { Probable } \\
\text { valencies }\end{array}$ & Likely site ${ }^{55}$ & $c /$ wt-ppm & $\begin{array}{l}\text { Effective } \\
c_{\text {dop }} / \text { ppm }\end{array}$ \\
\hline $\mathrm{Al}$ & $3+$ & $\mathrm{Ti}$ & $<14$ & $<123^{a}$ \\
$\mathrm{Mn}$ & $2+, 3+, 4+$ & $\mathrm{Ti}$ & $<217$ & $<88^{a}$ \\
$\mathrm{Fe}$ & $\mathbf{3 +}, 4+$ & $\mathrm{Ti}$ & $<40$ & $<167^{a}$ \\
$\mathrm{Cu}$ & $1+, 2+$ & $\mathrm{Ti}$ & $6.4 \pm 3.2$ & $47 \pm 24$ \\
$\mathrm{Zn}$ & $2+$ & $\mathrm{Ti}$ & $32 \pm 16$ & $225 \pm 113$ \\
$\mathrm{Y}$ & $3+$ & $\mathrm{Ba}+\mathrm{Ti}$ & $7.1 \pm 3.6$ & $19 \pm 10$ \\
$\mathrm{Eu}$ & $2+, 3+$ & $\mathrm{Ba}+\mathrm{Ti}$ & $8.2 \pm 4.1$ & $13 \pm 7$
\end{tabular}

Sum

$304 \pm 152$

${ }^{a}$ Concentrations below the detection limit of the method; these values were not included in calculating the total dopant concentration. analyses the pressure in the main chamber was below $1 \times 10^{-9}$ mbar. Two types of SIMS measurements were conducted: on each sample we measured short profiles up to a depth of $200 \mathrm{~nm}$ and long profiles up to $20 \mu \mathrm{m}$ in order to obtain both the profile through the surface-space charge and the profile in the uniform bulk phase with appropriate resolution. For the short profiles $15 \mathrm{keV} \mathrm{Ga}^{+}$ions were used for ToF analysis and $1 \mathrm{keV} \mathrm{Cs}^{+}$ions for sputtering. For the longer profiles $25 \mathrm{keV} \mathrm{Ga}^{+}$ions were used for ToF analysis (higher beam energy to receive the optimum signal-to-noise ratio for low ${ }^{18} \mathrm{O}$ intensities towards the end of the profiles) and $2 \mathrm{keV}$ $\mathrm{Cs}^{+}$ions were used for sputtering. In both cases a beam of electrons with $<20 \mathrm{eV}$ was used for charge compensation. As noted in the Introduction, charge compensation is one of the critical aspects in realizing high-quality SIMS measurements on $\mathrm{BaTiO}_{3}$ single crystals, primarily in order to prevent switching of the ferroelectric domains, which may lead to microcracking effects. $^{40}$ We ascertained that SIMS analysis of single crystal $\mathrm{BaTiO}_{3}$ was only successful when performed with low sputter currents and with careful charge compensation within a single and large ferroelectric domain.

All measurements were performed in bunched mode ${ }^{41}$ and the isotope fraction calculated from the molecular-ion signals according to: ${ }^{42}$

$$
n^{*}(x)=\frac{c_{18} \mathrm{O}}{c_{16} \mathrm{O}+c_{18} \mathrm{O}}=\frac{I\left({ }^{18} \mathrm{O}^{16} \mathrm{O}^{-}\right)}{2 I\left({ }^{16} \mathrm{O}^{16} \mathrm{O}^{-}\right)+I\left({ }^{18} \mathrm{O}^{16} \mathrm{O}^{-}\right)} .
$$

Solutions of the diffusion equation are formulated in terms of the corrected isotope fraction

$$
n_{\mathrm{r}}^{*}(x)=\frac{n^{*}(x)-n_{\mathrm{bg}}{ }^{*}}{n_{\mathrm{gas}}{ }^{*}-n_{\mathrm{bg}}{ }^{*}} .
$$

$n_{\text {gas }}{ }^{*}$, the ${ }^{18} \mathrm{O}$ isotope fraction in the annealing gas, was determined prior to the exchange experiments by SIMS analysis of a single crystal of silicon oxidized in the corresponding atmosphere, resulting in $n_{\text {gas }}{ }^{*}=0.937 \pm 0.002 . n_{\text {bg }}{ }^{*}$ is the measured background isotope fraction, which is the isotope fraction in a sample that has only been equilibrated. SIMS analysis of such a specimen yielded $n_{\mathrm{b}}{ }^{*}=(0.20 \pm 0.05) \times 10^{-2}$, which is, within experimental error, the natural abundance. ${ }^{57}$

Crater depths were determined post-analysis by interference microscopy on a Wyco NT1100 (Veeco Instruments Inc., Plainview, NY, USA).

\section{Results and discussion}

\subsection{Dopant distribution in the space-charge layer}

For the times and temperatures of the exchange experiments, oxygen vacancies, electron holes and electrons are all sufficiently mobile to attain equilibrium within the space-charge zone $\left(\nabla \tilde{\mu}_{\{\text {def }\}}=0\right)$. What about the cations? Cation diffusion in $\mathrm{BaTiO}_{3}$ is generally thought to become appreciable only at much higher temperatures; ${ }^{40,58,59}$ on the other hand, the diffusion distances involved in dopant accumulation in the space-charge zone are small, and therefore appreciable cation mobility is not necessarily required. In other words, various 
scenarios are possible: the dopant cation may be immobile and its concentration profile is therefore constant, $\left(\nabla c_{\text {dop }}=0\right)$ (this is sometimes termed the Mott-Schottky case); ${ }^{60,61}$ it may possess sufficient mobility and be given sufficient time, such that it is in electrochemical equilibrium, $\left(\nabla \tilde{\mu}_{\text {dop }}=0\right)$ (this is sometimes termed the Gouy-Chapman case); ${ }^{61}$ and time and/or mobility were neither negligible nor sufficient, and the profile is therefore neither of the extremes described above, but an intermediate case $\left[\left(\nabla c_{\text {dop }} \neq 0\right)\right.$ and $\left.\left(\nabla \tilde{\mu}_{\text {dop }} \neq 0\right)\right] .{ }^{61,62}$

Rather than make an assumption we determined experimentally the cation concentration profiles. Specifically we used the parallel detection of ToF-SIMS to extract $\mathrm{ZnO}^{-}$, $\mathrm{TiO}^{-}$and $\mathrm{BaO}^{-}$intensity profiles from the same ToF-SIMS depth profiles used to determine the isotope fraction profiles. We focus on the profile of the main dopant, zinc (see ICP-MS analysis, Table 1). In order to normalize the $\mathrm{Zn}$ signal with respect to a matrix species, one must take care to avoid mass interferences that arise not only from $\mathrm{Zn}$ and $\mathrm{Ti}$ both having five stable isotopes, but also from the oxygen isotope profile. As described in the Appendix, we found that the zinc intensity is best normalized according to

$$
\text { normalized } \mathrm{Zn} \text { intensity }=\frac{I_{\text {norm. }}(x)}{I_{\text {norm. }}(\infty)}=\frac{\frac{I_{64} \mathrm{Zn}^{16} \mathrm{O}^{-}}{I_{46} \mathrm{Ti}^{16} \mathrm{O}^{-}(x)}}{\frac{I_{64} \mathrm{Zn}^{16} \mathrm{O}^{-}(\infty)}{I{ }^{6} \mathrm{Ti}^{16} \mathrm{O}^{-}}(\infty)}
$$

In Fig. 2 we show a normalized zinc intensity profile through the space-charge layer after an isotope exchange experiment. The zinc profile is essentially constant; there is a slight decrease over the first $2-3 \mathrm{~nm}$, and this may be attributed to organic contaminations influencing the signals at mass $62\left({ }^{50} \mathrm{Ti}^{12} \mathrm{C}^{-}\right.$ interfering with $\left.{ }^{46} \mathrm{Ti}^{16} \mathrm{O}^{-}\right)$. In any case, the dopant concentration does not increase towards the surface. Hence, we conclude that the dopant is immobile within the spacecharge layer.

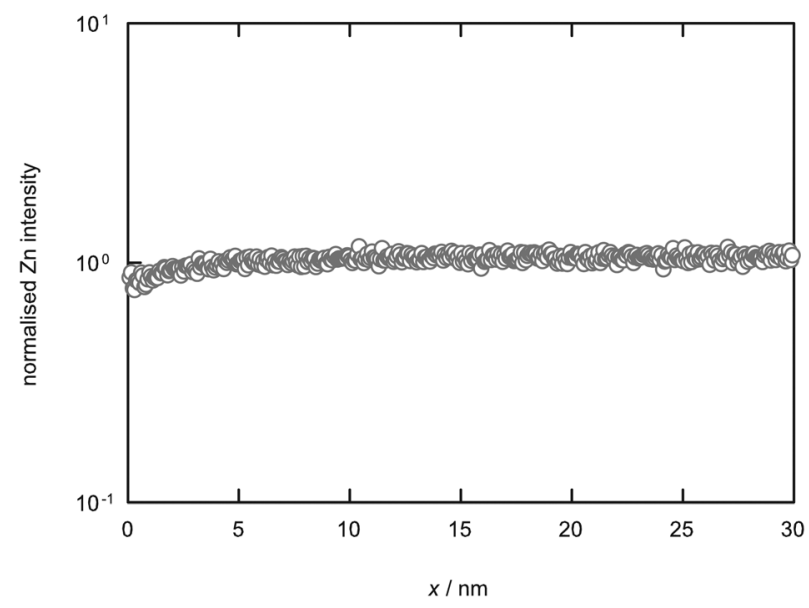

Fig. 2 Typical normalized zinc intensity profile in the first $30 \mathrm{~nm}$ of a single crystal. For each data point of the depth profile the normalized intensity is calculated as given by eqn (17) and solving several mass interference issues (see Appendix).

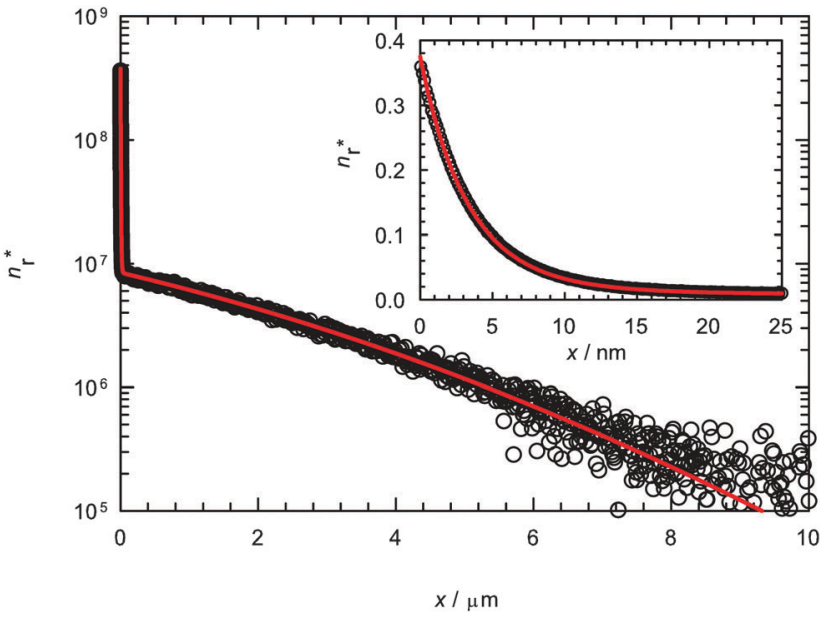

Fig. 3 Corrected isotope fraction $n_{\mathrm{r}}{ }^{*}$ against depth obtained from experiment (open circles) and numerical simulation (red line). The inset is an enlargement of the first $25 \mathrm{~nm}$. Isotope anneal at $T=1023 \mathrm{~K}, \mathrm{aO}_{2}=0.20$ for $t_{\mathrm{ex}}=1929 \mathrm{~s}$. Best fit obtained for $c_{\mathrm{dop}}=160 \mathrm{ppm}=2.5 \times 10^{24} \mathrm{~m}^{-3}$, $D^{\star}(\infty)=4.6 \times 10^{-15} \mathrm{~m}^{2} \mathrm{~s}^{-1}, k_{\mathrm{s}}^{*}=1.9 \times 10^{-11} \mathrm{~m} \mathrm{~s}^{-1}, \Phi_{0}=0.47 \mathrm{~V}$.

\subsection{Comparison of theoretical and experimental profiles}

A typical oxygen tracer diffusion profile obtained for single crystal $\mathrm{BaTiO}_{3}$ is shown in Fig. 3. As expected, ${ }^{42,43,45,63}$ two profile features were observed, which can be attributed to the surface space-charge layer, at short depths, and the normal bulk diffusion profile thereafter. In order to obtain values for $D^{*}(\infty), k_{\mathrm{S}}^{*}$ and $\Phi_{0}$, we compared visually experimentally determined and numerically calculated isotope profiles. The first $0.5 \mathrm{~nm}$ to $2 \mathrm{~nm}$ of each experimental profile were discarded, as this region corresponds to the interfacial core, and the numerical solution includes only the space-charge layer and the bulk phase. ${ }^{42}$ This does not affect the values of $D^{*}(\infty)$ obtained here (as the bulk profiles extend several micrometers), but it does give rise to some uncertainty in the values of $k_{\mathrm{s}}{ }^{*}$ and $\Phi_{0}$. These are of the order of $10 \%$, and thus acceptably small. It was found that with a doping concentration $c_{\text {dop }}=160 \mathrm{ppm}=2.5 \times 10^{24} \mathrm{~m}^{-3}$ all profiles could be described well. This value is in good agreement with results of the semi-quantitative ICP-MS analysis (see Table 1).

\subsection{Analysis of tracer diffusion coefficient $D^{*}$}

Tracer diffusion coefficients $D^{*}(\infty)$ are plotted as a function of oxygen activity $a \mathrm{O}_{2}$ and temperature $T$ in Fig. 4(a) and (b) respectively. From the former one sees that $D^{*}(\infty)$ is independent of oxygen activity. On the basis of the definition of the tracer diffusion coefficient [see eqn (12)],

$$
D^{*}(\infty)=f^{*} D_{\mathrm{V}} \frac{c_{\mathrm{V}_{\mathrm{O}}}(\infty)}{c_{\mathrm{O}_{\mathrm{O}}^{\times}}(\infty)},
$$

this result clearly indicates that the defect chemistry of this nominally undoped material is determined by acceptor-dopant impurities of fixed valence:

$$
m_{D^{*}(\infty)}=\left(\frac{\partial \ln D^{*}(\infty)}{\partial \ln a \mathrm{O}_{2}}\right)_{T} \approx\left(\frac{\partial \ln c_{\mathrm{V}_{0}}}{\partial \ln a \mathrm{O}_{2}}\right)_{T} \approx 0
$$



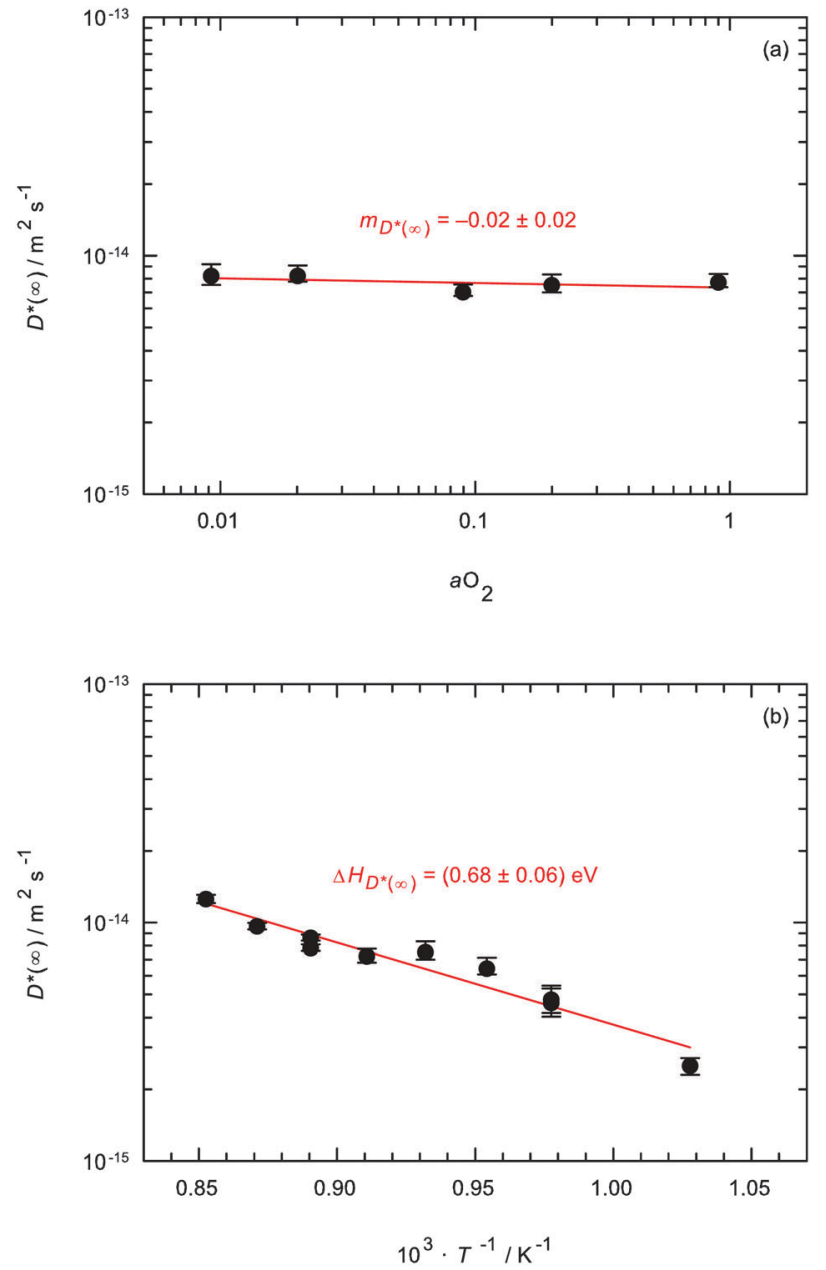

Fig. 4 Tracer diffusion coefficient $D^{*}(\infty)$ (a) as a function of oxygen activity $\mathrm{aO}_{2}$ (at $T=1073 \mathrm{~K}$ ) and (b) as a function of temperature $T$ (at $a \mathrm{O}_{2}=0.2$ ). The closed circles correspond to data points extracted from the measured diffusion profiles, the red lines show the best fits.

This is in good agreement with the results of the ICP-MS analysis (see Table 1).

In Fig. 4(b) the temperature dependence of the diffusion coefficients $D^{*}(\infty)$ is shown. Arrhenius-type behavior is seen:

$$
D^{*}(\infty)=D_{0}(\infty) \mathrm{e}^{-\frac{\Delta H_{D^{*}(\infty)}}{k_{\mathrm{B}} T}} .
$$

The activation enthalpy of isotope diffusion is determined to be $\Delta H_{D^{*}(\infty)}=(0.68 \pm 0.06) \mathrm{eV}$. From eqn (21) one sees that $\Delta H_{D^{*}(\infty)}$ can be expressed as the sum of the migration enthalpy and the generation enthalpy of oxygen vacancies:

$$
\begin{aligned}
\Delta H_{D^{*}(\infty)} & =-\left(\frac{\partial \ln D^{*}(\infty)}{\partial\left(1 / k_{\mathrm{B}} T\right)}\right)=-\left(\frac{\partial \ln D_{\mathrm{V}}}{\partial\left(1 / k_{\mathrm{B}} T\right)}\right)-\left(\frac{\partial \ln c_{\mathrm{V}_{\mathrm{O}}^{\bullet \bullet}}}{\partial\left(1 / k_{\mathrm{B}} T\right)}\right) \\
& =\Delta H_{\mathrm{mig}, \mathrm{V}}+\Delta H_{\mathrm{gen}, \mathrm{V}}
\end{aligned}
$$

As shown in Fig. 4(a) the defect chemistry of the samples is determined by acceptor-dopant impurities of fixed valence. This means the bulk charge neutrality condition is $c_{\text {dop }}=2 c_{\mathrm{V}_{\mathrm{O}}}$.
Therefore, the concentration of oxygen vacancies is independent of temperature, and the generation enthalpy of oxygen vacancies $\Delta H_{\text {gen,v }}$ is therefore zero. Consequently, the experimentally determined activation enthalpy is equal to the migration enthalpy of oxygen vacancies $\Delta H_{D^{*}(\infty)}=\Delta H_{\text {mig, } \mathrm{V}}=$ $(0.68 \pm 0.06) \mathrm{eV}$.

A comprehensive comparison with literature data is presented in Section 5.6, together with a detailed discussion of the data.

\subsection{Analysis of surface exchange coefficient $\boldsymbol{k}^{*}$}

The behavior of the surface exchange coefficient $k_{\mathrm{s}}{ }^{*}$ as a function of $a \mathrm{O}_{2}$ and $T$ is shown in Fig. 5(a) and (b) respectively. As a function of oxygen activity, the surface exchange coefficient $k_{\mathrm{s}}^{*}$ can be described by a power law

$$
k_{\mathrm{s}}^{*} \propto a \mathrm{O}_{2}^{m_{k_{\mathrm{s}}}}
$$

with the power-law exponent $m_{k_{\mathrm{s}}{ }^{*}}$. The fit to this behaviour is shown in Fig. 5(a), and yields $m_{k_{\mathrm{s}}{ }^{*}}=0.36 \pm 0.07$.
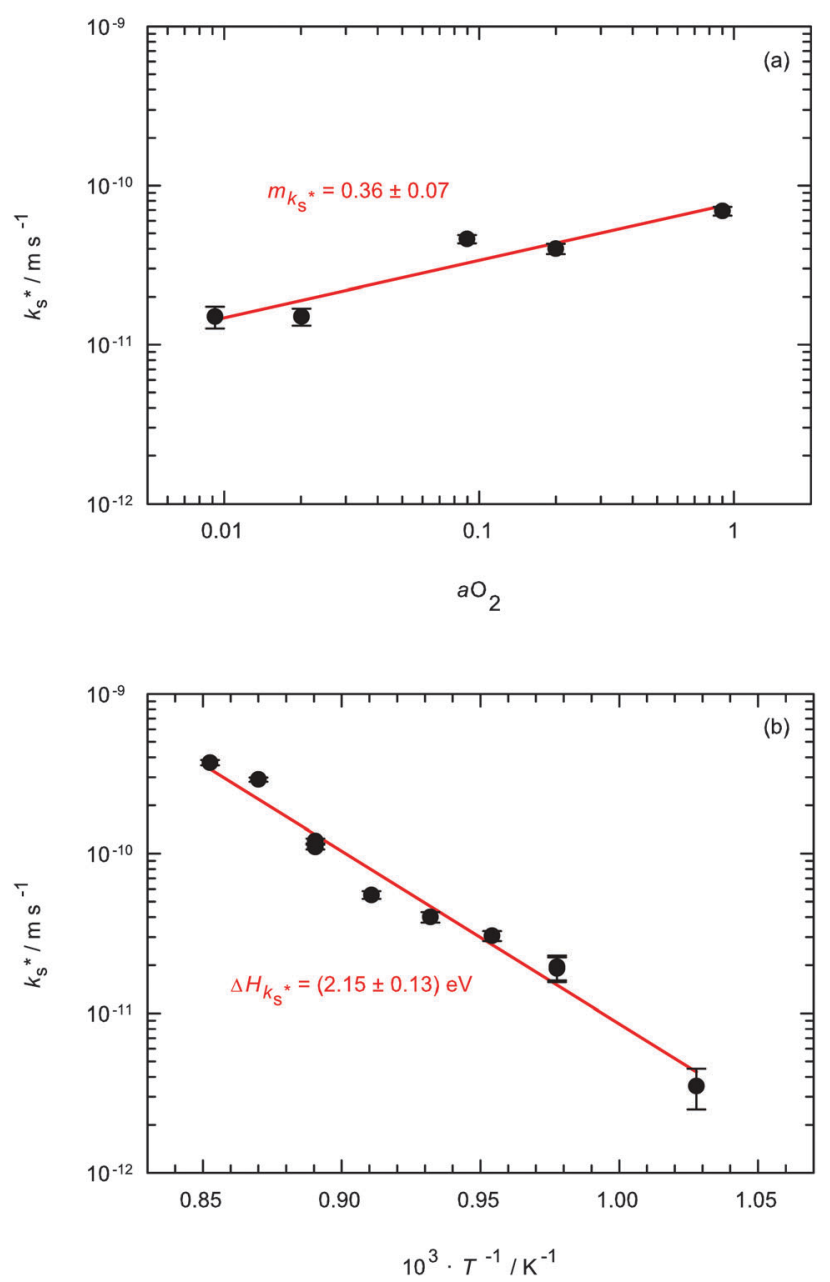

Fig. 5 Oxygen tracer surface exchange coefficient $k_{\mathrm{s}}{ }^{*}(\mathrm{a})$ as a function of oxygen activity $\mathrm{aO}_{2}$ (at $T=1073 \mathrm{~K}$ ) and (b) as a function of temperature $T$ (at $\mathrm{aO}_{2}=0.2$ ). The closed circles correspond to data points extracted from the measured diffusion profiles, the red lines show the best fits. 
De Souza ${ }^{54}$ found a universal empirical expression for the dependence of $k_{\mathrm{s}}^{*}$ on $a \mathrm{O}_{2}$,

$$
\frac{\partial \ln k_{\mathrm{s}}{ }^{*}}{\partial \ln a \mathrm{O}_{2}}=\frac{1}{4}-\frac{1}{2} \frac{\partial \ln c_{\mathrm{V}}}{\partial \ln a \mathrm{O}_{2}},
$$

that was able to explain the power-law exponents of five acceptor-doped perovskite and fluorite oxides. As shown in Fig. 4(a) the oxygen vacancy concentration in the bulk does not change with $a \mathrm{O}_{2}$ as it is fixed by the impurity acceptor doping. Eqn (23) would predict, therefore, a slope of $m_{k_{\mathrm{s}}{ }^{*}}=0.25$. Although the experimental value is within two standard deviations of this predicted value, the large error precludes further analysis.

Fig. 5(b) shows the temperature dependence of the surface exchange coefficients, and yields an activation energy of $\Delta H_{k_{\mathrm{s}}{ }^{*}}=$ $(2.15 \pm 0.13) \mathrm{eV}$. There are no comparable data in the literature for undoped or acceptor-doped $\mathrm{BaTiO}_{3}$. For Fe-doped $\mathrm{SrTiO}_{3}$ a slightly higher activation energy of (2.7-2.9) eV was found. ${ }^{64}$ For nominally undoped single crystals of strontium titanate a value of $(3.2 \pm 0.5) \mathrm{eV}$ was reported recently. ${ }^{43}$

\subsection{Analysis of space-charge potential $\Phi_{0}$}

In Fig. 6 we plot the space-charge potentials $\Phi_{0}$ extracted from the analysis as a function of oxygen activity $a \mathrm{O}_{2}$ and temperature $T$. The space-charge potential, it is emphasized, is not a materialspecific parameter; by analysing the dependences of $\Phi_{0}$ on $a \mathrm{O}_{2}$ and $T$, however, one can obtain the material- (and interface-)
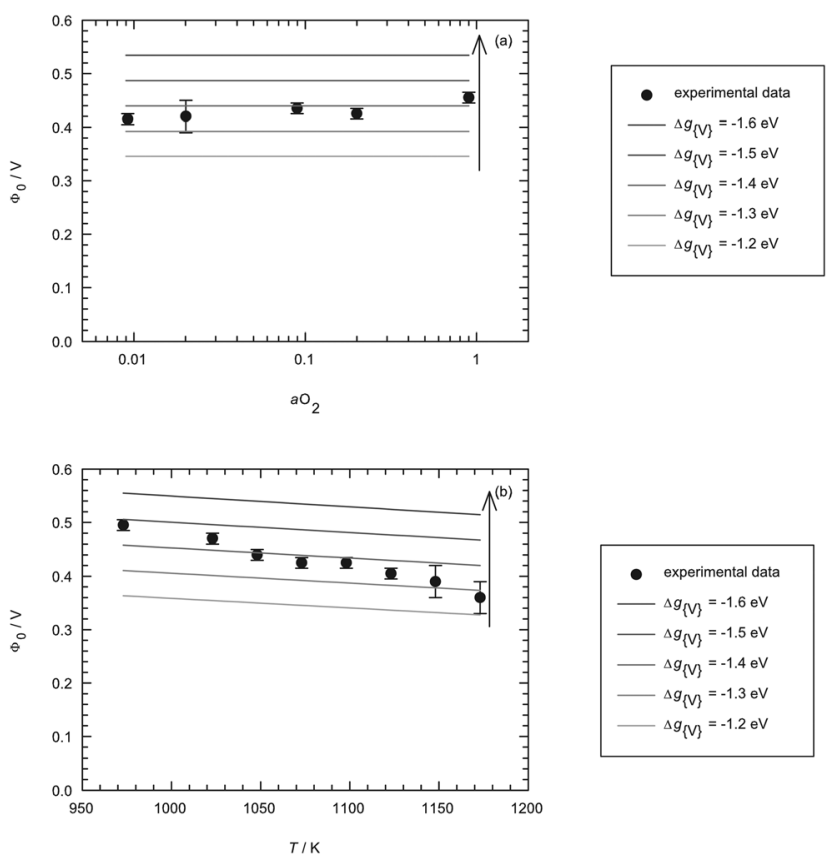

Fig. 6 Space-charge potential $\Phi_{0}$ (a) as a function of oxygen activity $\mathrm{aO}_{2}$ and (b) as a function of temperature $T$. The closed circles correspond to data points extracted from the measured diffusion profiles, the solid lines correspond to calculated space-charge potentials for increasingly negative values of $\Delta g_{\left\{\mathrm{v}_{\mathrm{o}}\right\}}=\{-1.2,-1.3,-1.4,-1.5,-1.6\} \mathrm{eV}$ (as indicated by the arrows), with $\Delta g_{\left\{h^{\bullet}\right\}}=\Delta g_{\left\{\mathrm{e}^{\prime}\right\}}=0$. The best agreement is found for $\Delta g_{\left\{\mathrm{v}_{\mathrm{O}}^{\bullet}\right\}}=-1.4 \mathrm{eV}$. specific parameters, that is, the fundamental driving energies for space-charge formation $\Delta g_{\{\text {def }\}}=g_{\{\text {def }\}}^{\mathrm{c}}-g_{\{\text {def }\}}^{\mathrm{b}}{ }^{51}$

There are two possibilities that lead to a space-charge layer depleted of oxygen vacancies, that is, to positive space-charge potentials: $\Delta g_{\left\{\mathrm{v}_{\mathrm{O}} \boldsymbol{\bullet}\right\}}<0, \Delta g_{\left\{\mathrm{h}^{\bullet}\right\}}<0$. The simplest approach would take only one driving energy and to set all others to zero. For example, $\Delta g_{\left\{\mathrm{v}_{\mathrm{O}}^{*}\right\}} \neq 0$ and $\Delta g_{\left\{\mathrm{h}^{\bullet}\right\}}=\Delta g_{\left\{\mathrm{e}^{\prime}\right\}}=0$. Surprisingly, one can describe the variation of $\Phi_{0}$ with both $a \mathrm{O}_{2}$ and $T$ with $\Delta g_{\left\{\mathrm{v}_{\mathrm{O}} \cdot \boldsymbol{}\right.}=-1.40 \mathrm{eV}$, as shown in Fig. 6. This is surprising because a value of $\Delta g_{\left\{\mathrm{v}_{\mathrm{o}}\right\}}=-1.42 \mathrm{eV}$ was obtained for nominally undoped $\mathrm{SrTiO}_{3}$ single crystals, ${ }^{43}$ and these (100) $\mathrm{SrTiO}_{3}$ crystals were treated to obtain a $\mathrm{TiO}_{2}$-terminated surface, whereas the (100) $\mathrm{BaTiO}_{3}$ crystals we used here were not treated and so probably have both $\mathrm{BaO}$ - and $\mathrm{TiO}_{2}$-terminated regions (the surface energies for the two different terminations being similar). ${ }^{65,66}$

Although the data of Fig. 6 are described well with this set of driving energies, there seem to be some small differences between the experimental values and the calculated curve, especially in Fig. 6(b) where the behaviour is underestimated at low temperatures, but overestimated at high temperatures. A closer description of these data can be achieved by having two non-zero driving energies, e.g., $\Delta g_{\left\{\mathrm{v}_{\mathrm{O}} \cdot\right\}}=-1.25 \mathrm{eV}$ and $\Delta g_{\{\mathrm{h} \bullet\}}=$ $-1.50 \mathrm{eV}$. The data points obtained for the two highest temperatures, however, show rather large errors bars. The isotope profiles within the space-charge layers in these two cases were not described as well by the numerical solution to eqn (13) as those profiles determined for lower anneal temperatures; this is due possibly to cation vacancies starting to become mobile at these high temperatures. Further experiments at lower temperatures and terminated surfaces could prove helpful in clearing up this problem.

\subsection{Literature overview for $D_{\mathrm{V}}$}

The oxygen tracer diffusion coefficients (and ionic conductivities) exhibited by a perovskite oxide depend on the concentration of oxygen vacancies in the material [see eqn (18)], and this of course may vary hugely between samples investigated by different groups because of differing dopant types and concentrations. Comparison of our data with literature data is best achieved, therefore, on the level of the vacancy diffusivity, $D_{\mathrm{V}}$. This quantity may be assumed to be independent of vacancy concentration, as long as the vacancies do not interact with each other or with the acceptor dopants. $^{67}$

Ionic conductivities $\sigma_{\text {ion }}$ reported in the literature were converted into vacancy diffusion coefficients by applying the Nernst-Einstein equation,

$$
D_{\mathrm{V}}=\frac{\sigma_{\text {ion }} k_{\mathrm{B}} T}{4 e^{2} c_{\mathrm{V}_{\mathrm{O}}^{\bullet}}} .
$$

In Fig. 7 we compare the oxygen vacancy diffusion coefficients from this work with literature data for barium titanate. There is good agreement between our data and the data obtained from equilibrium conductivities by Chan et al. for nominally 


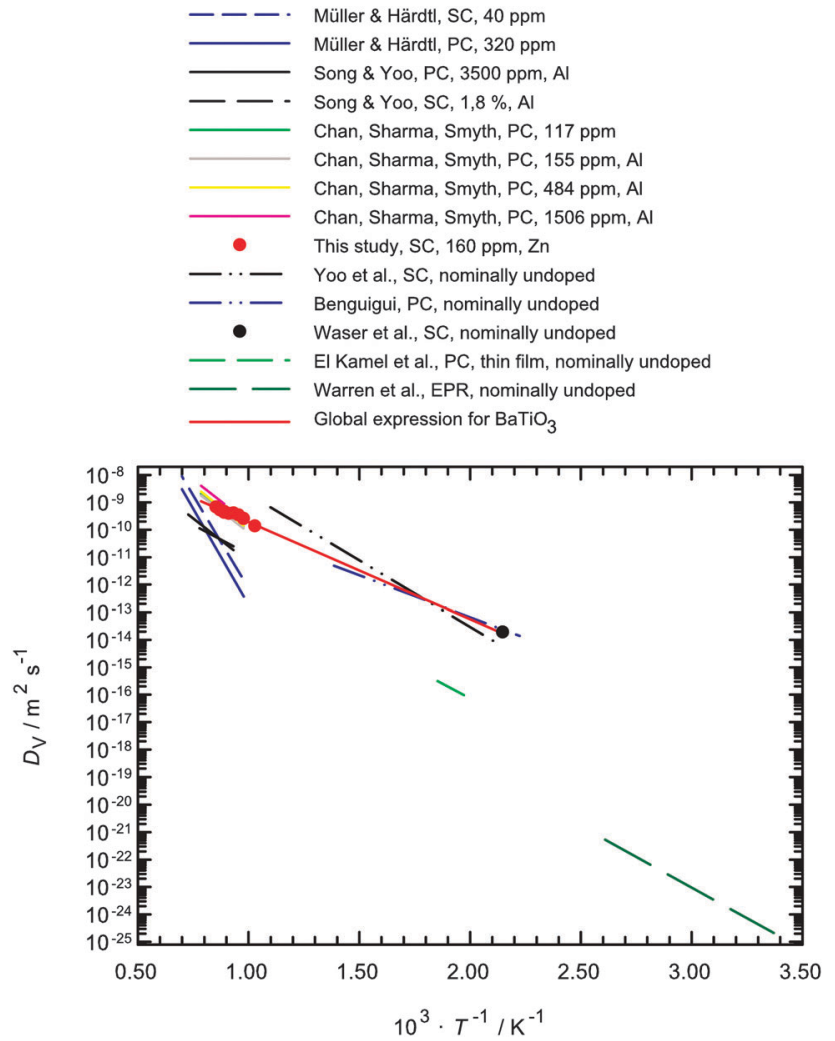

Fig. 7 Comparison of the oxygen vacancy diffusion coefficients $D_{\vee}$ as a function of inverse temperature for $\mathrm{BaTiO}_{3}$ from this work to selected data from the literature from Müller and Härdtl, ${ }^{21}$ Song and $\mathrm{YoO}^{22,26}$ and Chan, Sharma and Smyth, ${ }^{23,68}$ Yoo et al., ${ }^{70}$ Benguigui, ${ }^{69}$ Waser et al., ${ }^{7}$ El Kamel et al. ${ }^{71}$ and Warren et al. ${ }^{27} \mathrm{PC}$ refers to polycrystalline material, SC to single crystals. The dopant concentrations listed in the legend are effective dopant concentrations corresponding to $c_{\text {dop }}$ in eqn (2).

undoped $^{23}$ as well as for various Al-doped samples. ${ }^{68}$ Moreover, in a different temperature region also the data set from Benguigui $^{69}$ and the data point from Waser et al. ${ }^{7}$ follow the trend of our data. Taking the data sets from Chan et al. for $c_{\text {dop }}=155 \mathrm{ppm}$ (six data points), Waser (one data point), Benguigui (six data points) and this work (six data points), we obtain a global expression for the oxygen vacancy diffusivity $D_{\mathrm{V}}$ in barium titanate in the temperature range $466<$ $T / \mathrm{K}<1273:$

$$
\ln \left[D_{\mathrm{V}}(T) / \mathrm{m}^{2} \mathrm{~s}^{-1}\right]=-\left(6.43_{-0.99}^{+1.17}\right)-\frac{(0.70 \pm 0.04) \mathrm{eV}}{k_{\mathrm{B}} T}
$$

Fig. 7 shows a lot of scatter in the data and data sets that obviously deviate from the global expression. Besides, possible errors in performing and analysing transport experiments, there may also be interactions between oxygen vacancies and dopants, and these become important at lower temperatures. $^{67}$

Fig. 8 shows the vacancy diffusivity obtained for barium titanate in comparison with values for other perovskite oxides. One sees that isothermal values of $D_{\mathrm{V}}$ for all these different compositions vary by only 1 to 1.5 orders of magnitude, as first noted by Mizusaki et al. ${ }^{72}$ and Kilner et al. ${ }^{73}$

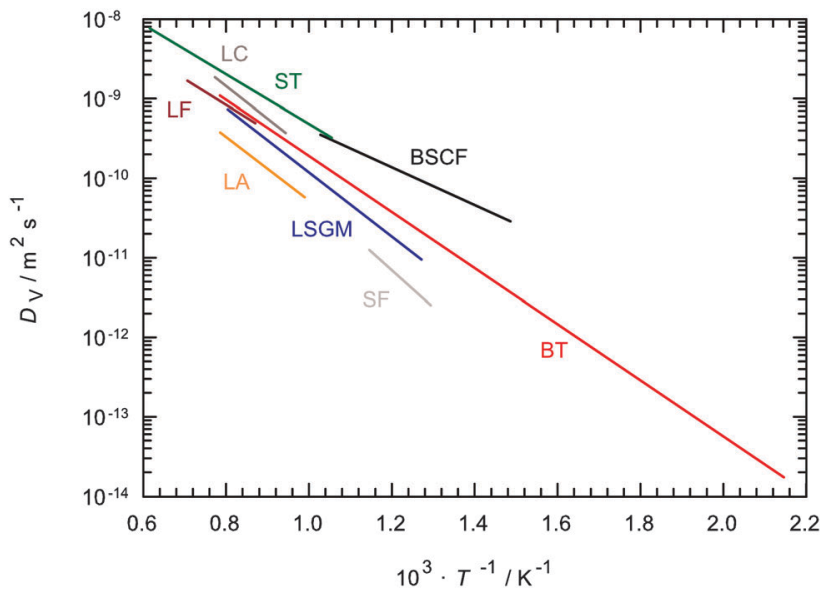

Fig. 8 Oxygen vacancy diffusion coefficients $D_{V}$ as a function of inverse temperature: (A) $\mathrm{Ba}_{0.5} \mathrm{Sr}_{0.5} \mathrm{Co}_{0.8} \mathrm{Fe}_{0.2} \mathrm{O}_{3-\delta}$ (BSCF5582, thin film, $\left.D^{*}\right){ }_{7}^{74}$ (B) $\mathrm{SrFeO}_{3}$ (thin film, $\left.D^{\star}\right) ; 7^{75}$ (C) $\mathrm{La}_{0.9} \mathrm{Sr}_{0.1} \mathrm{Ga}_{0.8} \mathrm{Mg}_{0.2} \mathrm{O}_{3-\delta}\left(\mathrm{LSGM}, D^{*}\right) 7^{76}$ (D) $\mathrm{LaFeO}_{3}\left(D^{*}\right) i^{.53}(\mathrm{E}) \mathrm{LaAlO}_{3}\left(\sigma_{\text {ion }}\right) 7^{72}(\mathrm{~F}) \mathrm{LaCoO}_{3}$ (global expression from $D^{\delta}$ and $\left.D^{\star}\right) ;{ }^{77,78}(\mathrm{G}) \mathrm{SrTiO}_{3}$ (global expression from various types of methods); ${ }^{43}$ (H) $\mathrm{BaTiO}_{3}$ [global expression from this work, eqn (25)].

Table 2 is a summary of activation enthalpies of oxygen vacancy migration obtained for $\mathrm{BaTiO}_{3}$ by various experimental and computational methods. The value given by the universal expression of $(0.70 \pm 0.04) \mathrm{eV}$ is in good agreement with the value from Mott-Littleton calculations of Lewis et al. $(0.77 \mathrm{eV}) .^{79}$

The process of oxygen-ion migration in an $\mathrm{ABO}_{3}$ perovskite consists of an oxygen-ion forcing its way through a small aperature formed by two $\mathrm{A}$ cations and one $\mathrm{B}$ cation, $\Delta_{\mathrm{AAB}}$. The radius of a sphere that just fits through this $\Delta_{\mathrm{AAB}}$ aperature can be expressed in terms of the lattice constant $a$ and the radii of the two cations $r_{\mathrm{A}}$ and $r_{\mathrm{B}}$, as first recognised by Kilner and Brook: ${ }^{80}$

$$
r_{\mathrm{c}}=\frac{a\left(\frac{3}{4} a-2^{\frac{1}{2}} r_{\mathrm{B}}\right)-\left(r_{\mathrm{A}}-r_{\mathrm{B}}\right)\left(r_{\mathrm{A}}+r_{\mathrm{B}}\right)}{2\left(r_{\mathrm{A}}-r_{\mathrm{B}}\right)+2^{\frac{1}{2}} a}
$$

One expects, from this simple static model, the activation enthalpy to increase with decreasing critical radius, or equivalently, with increasing inverse critical radius. In Fig. 9 we plot the experimentally determined activation enthalpy of migration for various perovskite oxides against the inverse critical radius. One perceives that the expected trend is indeed observed, but, one could argue, the $A^{\mathrm{III}} B^{\mathrm{III}} \mathrm{O}_{3}$-based perovskites lie on a slightly different line to that for the $A^{\mathrm{II}} B^{\mathrm{IV}} \mathrm{O}_{3}$-based perovskites. The limited amount of data, however, prevents further analysis.

\section{Conclusions}

We studied oxygen tracer diffusion in single crystals of $\mathrm{BaTiO}_{3}$ in a range of temperatures in which this perovskite oxide adopts cubic symmetry. The key points to emerge from our study can be summarized as follows:

(1) ${ }^{18} \mathrm{O}$ isotope profiles, which were obtained by ToF-SIMS depth profiling at high depth resolution, exhibited two features. 
Table 2 Comparison of oxygen vacancy migration enthalpies for barium titanate. PC refers to polycrystalline material, SC to single crystals, the listed dopant concentrations are effective values corresponding to $c_{\text {dop }}$ in eqn (2)

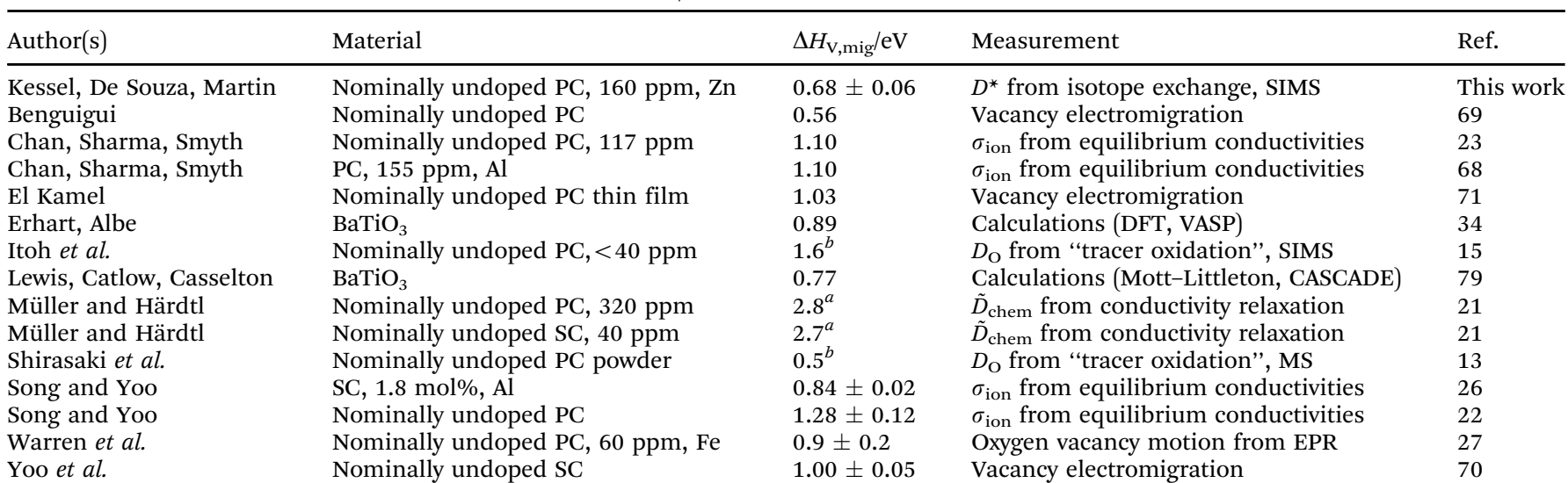

${ }^{a}$ In these measurements the authors' conversion of $\tilde{D}_{\text {chem }}$ to $D_{\mathrm{V}_{0}^{*}}$ is based on the use of a questionable thermodynamic factor. ${ }^{b}$ In these "tracer oxidation" experiments the oxygen tracer is incorporated in both a chemical potential gradient and the potential gradient of the isotope.

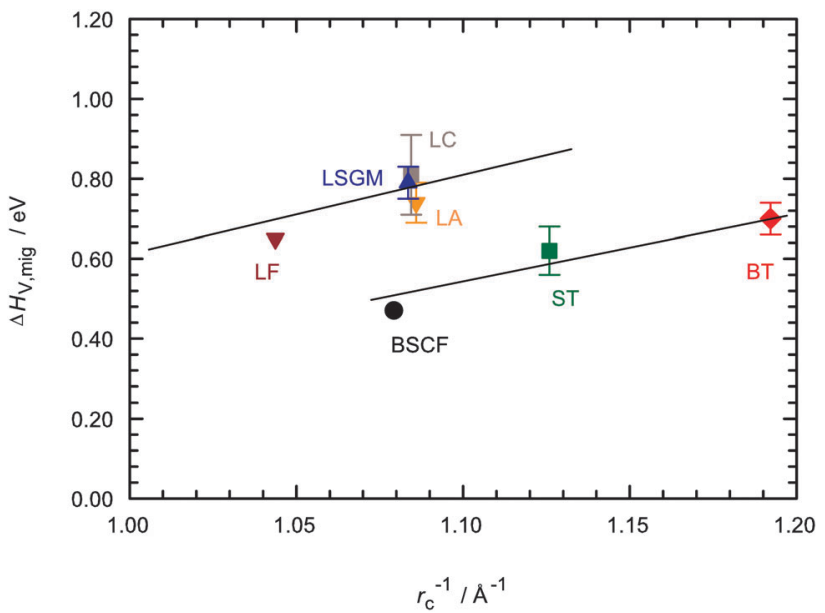

Fig. 9 Comparison of the oxygen vacancy migration enthalpy $\Delta H_{\mathrm{V}, \mathrm{mig}}$ as a function of the inverse critical radius $r_{\mathrm{C}}$ for the global expression for $\mathrm{BaTiO}_{3}$ eqn (25) to selected data from the literature for $\mathrm{Ba}_{0.5} \mathrm{Sr}_{0.5} \mathrm{Co}_{0.8} \mathrm{Fe}_{0.2} \mathrm{O}_{3}$ (BSCF5582, thin film, $\left.D^{*}\right){ }_{1}^{74} \mathrm{La}_{0.9} \mathrm{Sr}_{0.1} \mathrm{Ga}_{0.8} \mathrm{Mg}_{0.2} \mathrm{O}_{3-\delta}\left(\mathrm{LSGM}, D^{*}\right),{ }^{76} \mathrm{LaFeO}_{3}$ $\left(D^{\star}\right),{ }^{53} \mathrm{LaAlO}_{3}\left(\sigma_{\text {ion }}\right),{ }^{72} \mathrm{LaCoO}_{3}$ (universal expression from $D^{\delta}$ and $\left.D^{\star}\right)^{77,78}$ and $\mathrm{SrTiO}_{3}$ (universal expression from various types of methods). ${ }^{43}$

We showed that the entire profile, i.e. both features, could be described by a single solution of the diffusion equation that takes into account a surface space-charge depletion layer.

(2) Analysis of the isotope profiles yielded surface exchange coefficients $k_{\mathrm{s}}{ }^{*}$, space-charge potentials $\Phi_{0}$ and bulk diffusion coefficients $D^{*}(\infty)$ as a function of $p \mathrm{O}_{2}$ and $T$.

(3) The diffusivity of oxygen vacancies, $D_{\mathrm{V}}$, obtained in this study was compared with data from the literature. On this basis, we obtained the activation enthalpy for the migration of oxygen vacancies in cubic $\mathrm{BaTiO}_{3}$ to be $\Delta H_{\text {mig,v }}=0.7 \mathrm{eV}$.

(4) A comparison of $\Delta H_{\text {mig, },}$ for $\mathrm{BaTiO}_{3}$ with literature data for other perovskites suggested that $\mathrm{A}^{\mathrm{II}} \mathrm{B}^{\mathrm{IV}} \mathrm{O}_{3}$ perovskite oxides behave differently to $\mathrm{A}^{\mathrm{III}} \mathrm{B}^{\mathrm{III}} \mathrm{O}_{3}$ perovskite oxides.

\section{Appendix: mass interferences analysing $\mathrm{Zn}$ profiles and their circumvention}

Determining the $\mathrm{Zn}$ dopant concentration profile (normalised to the $\mathrm{Zn}$ concentration in the bulk) is far from straightforward. There are several mass interferences that make it difficult to isolate specific secondary ion intensities from a given mass channel. For example, at mass 80 one expects contributions from the following secondary ion species:

$I($ mass 80 $)=I\left({ }^{64} \mathrm{Zn}^{16} \mathrm{O}^{-}\right)+I\left({ }^{48} \mathrm{Ti}^{16} \mathrm{O}_{2}{ }^{-}\right)+I\left({ }^{46} \mathrm{Ti}^{18} \mathrm{O}^{16} \mathrm{O}^{-}\right)$

In order to separate the signals of these three species, one requires a SIMS mass resolution of $m / \Delta m=8980$. The SIMS mass resolution we obtained for these insulating, ferroelectric samples was, however, only about 7000 (full width at half maximum), so that we were not able to distinguish between these species. Alternative masses do not provide a superior solution: ${ }^{64} \mathrm{Zn}$ is the main zinc isotope with the best signal-tonoise ratio; the other zinc isotopes, all at higher masses, are affected in the same way or by even more mass interferences.

In order to obtain only the intensity of the zinc species, one needs to determine independently the intensities of ${ }^{48} \mathrm{Ti}^{16} \mathrm{O}_{2}{ }^{-}$ and ${ }^{46} \mathrm{Ti}^{18} \mathrm{O}^{16} \mathrm{O}^{-}$. Calculating the intensity of ${ }^{48} \mathrm{Ti}^{16} \mathrm{O}_{2}{ }^{-}$is possible with the help of the natural abundances $a$ of the $\mathrm{Ti}$ isotopes

$$
I\left({ }^{48} \mathrm{Ti}^{16} \mathrm{O}_{2}{ }^{-}\right)=\frac{a\left({ }^{48} \mathrm{Ti}\right)}{a\left({ }^{46} \mathrm{Ti}\right)} \cdot I\left({ }^{46} \mathrm{Ti}^{16} \mathrm{O}_{2}{ }^{-}\right),
$$

While calculation of the ${ }^{46} \mathrm{Ti}^{18} \mathrm{O}^{16} \mathrm{O}^{-}$intensity by the help of the measured isotope fraction $n^{*}$ [see eqn (15)]

$$
I\left({ }^{46} \mathrm{Ti}^{18} \mathrm{O}^{16} \mathrm{O}^{-}\right)=\frac{2 n^{*} I\left({ }^{46} \mathrm{Ti}^{16} \mathrm{O}_{2}\right)^{2}}{\left(1-n^{*}\right)} .
$$

In both eqn (A.2) and (A.3) the intensity of ${ }^{46} \mathrm{Ti}^{16} \mathrm{O}_{2}{ }^{-}$is needed: it can be measured without any mass interference. 
Therefore, eqn (A.1)-(A.3) can be rearranged to

$$
\begin{aligned}
I\left({ }^{64} \mathrm{Zn}^{16} \mathrm{O}^{-}\right)= & I(\operatorname{mass} 80)-\frac{a\left({ }^{48} \mathrm{Ti}\right)}{a\left({ }^{46} \mathrm{Ti}\right)} I\left({ }^{46} \mathrm{Ti}^{16} \mathrm{O}_{2}{ }^{-}\right) \\
& -\frac{2 n^{*} I\left({ }^{46} \mathrm{Ti}^{16} \mathrm{O}_{2}\right)^{2}}{\left(1-n^{*}\right)} .
\end{aligned}
$$

In order to analyze the variation of the zinc concentration with sputter depth, the intensity of ${ }^{64} \mathrm{Zn}^{16} \mathrm{O}^{-}$needs to be normalized to the intensity of a matrix element. In this case we chose ${ }^{46} \mathrm{Ti}^{16} \mathrm{O}^{-}$for normalization as this species should not be influenced by any mass interference:

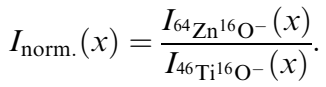

In a second step $I_{\text {norm. }}(x)$ is normalized to the value in the bulk $I_{\text {norm. }}(\infty)$ so that the resulting "normalized $\mathrm{Zn}$ intensity" directly shows the variation of the zinc concentration at any position in the space-charge layer compared to that in the bulk (see Fig. 2):

$$
\text { normalized } \mathrm{Zn} \text { intensity }=\frac{I_{\text {norm. }}(x)}{I_{\text {norm. }}(\infty)}=\frac{\frac{I_{64} \mathrm{Zn}^{16} \mathrm{O}^{-}}{I_{46} \mathrm{Ti}^{16} \mathrm{O}^{-}}(x)}{\frac{I_{64} \mathrm{Zn}^{16} \mathrm{O}^{-}}{I_{46} \mathrm{Ti}^{16} \mathrm{O}^{-}}(\infty)} .
$$

\section{Acknowledgements}

We gratefully acknowledge P. Dollase for experimental assistance and the Central Division of Analytical Chemistry $(\mathrm{ZCH})$ of the Forschungszentrum Jülich for the ICP-MS analysis. M. Kessel is grateful to the Fonds der Chemischen Industrie, Germany, for a scholarship.

\section{Notes and references}

1 H. Kishi, Y. Mizuno and H. Chazono, Jpn. J. Appl. Phys., 2003, 42, 1.

2 R. C. Buchanan, Ceramic Materials for Electronics, Dekker, New York, 2004.

3 M. R. Opitz, K. Albertsen, J. J. Beeson, D. F. Hennings, J. L. Routbort and C. A. Randall, J. Am. Ceram. Soc., 2003, 86, 1879.

4 J. Hagemann and D. F. Hennings, J. Am. Ceram. Soc., 1981, 64, 590 .

5 Y. Sakabe, Am. Ceram. Soc. Bull., 1987, 66, 1338.

6 J. F. Scott, Ferroelectr. Rev., 1998, 1, 1.

7 R. Waser, T. Baiatu and K. H. Haerdtl, J. Am. Ceram. Soc., 1990, 73, 1645.

8 J. Daniels, K. H. Härdtl and R. Wernicke, Philips Tech. Rev., 1978-1979, 38, 73.

9 D. C. Sinclair and A. R. West, J. Appl. Phys., 1989, 66, 3850. 10 K.-D. Becker, M. Schrader, H.-S. Kwon and H.-I. Yoo, Phys. Chem. Chem. Phys., 2009, 11, 3082.

11 M. C. Ferrarelli, C. C. Tan and D. C. Sinclair, J. Mater. Chem., 2011, 21, 6292.
12 H.-I. Yoo and D.-K. Lee, Phys. Chem. Chem. Phys., 2003, 5, 2212-2218.

13 S. Shirasaki, H. Yamamura, H. Haneda, K. Kagekawa and J. Moori, J. Chem. Phys., 1980, 73, 4640.

14 J. Itoh, D.-C. Park, N. Ohashi, I. Sakaguchi, I. Yamashita, H. Haneda and J. Tanaka, Jpn. J. Appl. Phys., 2002, 41, 3798.

15 J. Itoh, D.-C. Park, N. Ohashi, I. Sakaguchi, I. Yamashita, H. Haneda and J. Tanaka, J. Ceram. Soc. Jpn., 2002, 110, 495. 16 A. Hasegawa, S. Fujitsu, K. Koumoto and H. Yanagida, Jpn. J. Appl. Phys., 1991, 30, 1252.

17 T. Frömling, J. Hou, W. Preis, W. Sitte, H. Hutter and J. Fleig, J. Appl. Phys., 2011, 110, 043531.

18 M. Kessel, R. A. De Souza, H.-I. Yoo and M. Martin, Appl. Phys. Lett., 2010, 97, 021910.

19 C. Schaffrin, Phys. Status Solidi A, 1976, 35, 79.

20 R. Wernicke, Philips Res. Rep., 1976, 31, 526.

21 A. Müller and K. H. Härdtl, Appl. Phys. A: Mater. Sci. Process., 1989, 49, 75.

22 C.-R. Song and H.-I. Yoo, Solid State Ionics, 1999, 120, 141.

23 N.-H. Chan, R. K. Sharma and D. M. Smyth, J. Am. Ceram. Soc., 1981, 64, 556.

24 J. Maier, G. Schwitzgebel and H.-J. Hagemann, J. Solid State Chem., 1985, 58, 1.

25 J. Nowotny and M. Rekas, Ceram. Int., 1994, 20, 225.

26 C.-R. Song and H.-I. Yoo, J. Am. Ceram. Soc., 2000, 83, 773.

27 W. L. Warren, K. Vandheusden, D. Dimos, G. E. Pike and B. A. Tuttle, J. Am. Ceram. Soc., 1996, 79, 536.

28 S. H. Cha and Y. H. Han, J. Appl. Phys., 2006, 100, 104102.

29 B. S. Kang, S. K. Choi and C. H. Park, J. Appl. Phys., 2003, 94, 1904.

30 L. Chen, X. M. Xiong, H. Meng, P. Lv and J. X. Zhang, Appl. Phys. Lett., 2006, 89, 071916.

31 I. Fujii, M. Ugorek, Y. Han and S. Trolier-McKinstry, J. Am. Ceram. Soc., 2010, 93, 1081.

32 G. V. Lewis and C. R. A. Catlow, Radiat. Eff., 1983, 73, 307.

33 B. P. Uberuaga and L. J. Vernon, Solid State Ionics, 2013, 253, 18.

34 P. Erhart and K. Albe, J. Appl. Phys., 2007, 102, 084111.

35 R. J. Chater, S. Carter, J. A. Kilner and B. C. H. Steele, Solid State Ionics, 1992, 53-56, 859.

36 R. A. De Souza and M. Martin, MRS Bull., 2009, 34, 907.

37 J. Kilner, S. Skinner and H. Brongersma, J. Solid State Electrochem., 2011, 15, 861.

38 A. von Hippel, Rev. Mod. Phys., 1950, 22, 221.

39 W. Heywang, J. Am. Ceram. Soc., 1964, 47, 484.

40 S. Koerfer, R. A. De Souza, H.-I. Yoo and M. Martin, Solid State Sci., 2008, 10, 725.

41 R. A. De Souza, J. Zehnpfenning, M. Martin and J. Maier, Solid State Ionics, 2005, 176, 1465.

42 R. A. De Souza and M. Martin, Phys. Chem. Chem. Phys., 2008, 10, 2356.

43 R. A. De Souza, V. Metlenko, D. Park and T. E. Weirich, Phys. Rev. B: Condens. Matter Mater. Phys., 2012, 85, 174109.

44 R. A. De Souza, F. Gunkel, S. Hoffmann-Eifert and R. Dittmann, Phys. Rev. B: Condens. Matter Mater. Phys., 2014, 89(24), 241401. 
45 R.-V. Wang and P. C. McIntyre, J. Appl. Phys., 2005, 97, 023508.

46 N.-H. Chan and D. M. Smyth, J. Electrochem. Soc., 1976, 123, 1584.

47 D. M. Smyth, Ferroelectrics, 1994, 151(1), 115.

48 J.-Y. Kim, C.-R. Song and H.-I. Yoo, J. Electroceram., 1997, 1, 27.

49 A. M. J. H. Seuter, Philips Res. Rep., Suppl., 1974, 3, 1.

50 J. Jamnik, J. Maier and S. Pejovnik, Solid State Ionics, 1995, 75, 51.

51 R. A. De Souza, Phys. Chem. Chem. Phys., 2009, 11, 9939-9969.

52 W. Goepel and H.-D. Wiemhoefer, Statistische Thermodynamik (in German), Spektrum Verlag, Heidelberg, Berlin, 2000.

53 T. Ishigaki, S. Yamauchi, K. Kishio, J. Mizusaki and K. Fueki, J. Solid State Chem., 1988, 73, 179.

54 R. A. De Souza, Phys. Chem. Chem. Phys., 2006, 8, 890.

55 C. L. Freeman, J. A. Dawson, H.-R. Chen, J. H. Harding, L.-B. Ben and D. C. Sinclair, J. Mater. Chem., 2011, 21, 4861-4868.

56 R. A. De Souza and R. J. Chater, Solid State Ionics, 2005, 176, 1915.

57 K. J. R. Rosman and P. D. P. Taylor, Pure Appl. Chem., 1998, 70, 217.

58 W. Preis and W. Sitte, Solid State Ionics, 2006, 177, 3093.

59 H.-I. Yoo, C.-E. Lee, R. A. De Souza and M. Martin, Appl. Phys. Lett., 2008, 92, 252103.

60 S. M. Sze, Semiconductor Devices, John Wiley \& Sons Ltd, New York, 1985.

61 J. Maier, Physical Chemistry of Ionic Materials, John Wiley \& Sons Ltd, Chichester, 2004.

62 D. F. Evans and H. Wennerström, The Colloidal Domain, VCH Publishers, New York, 1994.

63 S. Gottschalk, H. Hahn, S. Flege and A. G. Balogh, J. Appl. Phys., 2008, 104, 114106.
64 M. Leonhardt, R. A. De Souza, J. Claus and J. Maier, J. Electrochem. Soc., 2002, 149, J19.

65 J. Padilla and D. Vanderbilt, Surf. Sci., 1998, 418, 64.

66 E. Heifets, R. I. Eglitis, E. A. Kotomin, J. Maier and G. Borstel, Phys. Rev. B: Condens. Matter Mater. Phys., 2001, 64, 235417.

67 M. Schie, R. Waser and R. A. De Souza, J. Phys. Chem. C, 2014, 118, 15185.

68 N.-H. Chan, R. K. Sharma and D. M. Smyth, J. Am. Ceram. Soc., 1982, 65, 167.

69 L. Benguigui, J. Phys. Chem. Solids, 1973, 34, 573.

70 H.-I. Yoo, M.-W. Chang, T.-S. Oh, C.-E. Lee and K. D. Becker, J. Appl. Phys., 2007, 102, 93701.

71 F. El Kamel, P. Gonon, F. Jomni and B. Yangui, J. Appl. Phys., 2006, 100, 54107.

72 J. Mizusaki, I. Yasuda, J. Shimoyama, S. Yamauchi and F. Fueki, J. Electrochem. Soc., 1993, 140, 467.

73 J. A. Kilner, R. A. De Souza and I. C. Fullarton, Solid State Ionics, 1996, 86-88, 703.

74 L. Wang, R. Merkle, J. Maier, T. Acartürk and U. Starke, Appl. Phys. Lett., 2009, 94, 071908.

75 L. Wang, R. Merkle and J. Maier, J. Electrochem. Soc., 2010, 157, B1802.

76 T. Ishihara, J. A. Kilner, M. Honda and Y. Takita, J. Am. Chem. Soc., 1997, 119, 2747.

77 K. Fueki, J. Mizusaki, S. Yamauchi, T. Ishigaki and Y. Mima, in Reactivity of Solids, ed. P. Barret and L.-C. Dufour, Elsevier, Amsterdam, 1985, p. 339.

78 T. Ishigaki, S. Yamauchi, J. Mizusaki, K. Fueki and H. Tamura, J. Solid State Chem., 1984, 54, 100.

79 G. V. Lewis, C. R. A. Catlow and R. E. W. Casselton, J. Am. Ceram. Soc., 1985, 68, 555.

80 J. A. Kilner and R. J. Brook, Solid State Ionics, 1982, 6, 237. 